\title{
Effect of low-level laser therapy on osseointegration of titanium dental implants in ovariectomized rabbits: biomechanics and micro-CT analysis
}

\author{
Mustafa Karakaya ${ }^{1 *}$ and Ahmet Emin Demirbaş ${ }^{2}$
}

\begin{abstract}
Purpose: The primary aim of this study is to assess, in an animal model, whether biostimulation of osteoporotic bone with low-level laser therapy improves the osseointegration of dental implants.

Material and methods: Twenty-two female rabbits were randomly divided into two groups: sham-ovariectomy and bilateral-ovariectomy. Laser therapy was applied to the implants placed in the right tibial bones and was not applied to implants placed in the left tibial bones. The periotest device was used for the stability test. Periotest values were recorded after the implantation (TO) and when the animals were euthanized (T1). The removal torque test and micro-computed tomography examination were evaluated.

Results: As a result of removal torque, the mean of ovariectomy-laser group $(56.1 \pm 5.1 \mathrm{Ncm}$ ) was higher than sham-ovariectomy group $(55.4 \pm 18.5 \mathrm{Ncm})(p=0.9)$. In periotest analysis, a significant difference was found between the values of T1 and T0 in all groups, except sham-ovariectomy group ( $p<0.05)$; and the highest difference was found in the ovariectomy-laser group. Micro-CT examination demonstrated that ovariectomy-laser group showed an increase of implant-bone contact when compared with ovariectomy $(p<0.05)$.

Conclusions: The values obtained from biomechanical tests and micro-CT in the ovariectomy-laser group were significantly higher than the ovariectomy group and achieved the values in the healthy bone.
\end{abstract}

Keywords: Dental implant, Osseointegration, Low-level laser therapy, Osteoporosis, Micro-CT

\section{Introduction}

Dental implants are frequently used in prosthetic treatment with the aim of restoring the loss of esthetic and function. Osseointegration is very important in the success of dental implants and is defined as "the direct structural and functional connection between a loadbearing implant surface and bone" [1]. One of the factors influencing the osseointegration is the quality of the bone surrounding the implant. In the presence of intense bone, the percentage of implant-to-bone contact

\footnotetext{
* Correspondence: mk.karakayaa@gmail.com; mustafakarakaya@erciyes.edu.tr ${ }^{1}$ Sancaktepe Oral and Dental Health Hospital, Department of Oral and Maxillofacial Surgery, Ministry of Health, Istanbul, Turkey Full list of author information is available at the end of the article
}

increases and the implant is more stable during recovery [2]. Low or poor bone quality and insufficient primary stabilization are important reasons for implant failure. Osteoporosis is one of the diseases that cause low bone quality. It has been defined as a systemic skeletal disease characterized by low bone mass and microarchitectural deterioration of bone tissue, with consequent increase in bone fragility and susceptibility to fracture [3]. Osteoporosis-related changes in the jaws are not different from the changes in the other bones of the body [4]. Bone density and quality in aging and osteoporosis are negatively affected by the decrease in cell proliferation, cellular synthesis activity, cellular sensitivity, and in the number of mesenchymal stem cells [5]. Decreased bone 
mass and bone mineral density have been reported to cause delayed healing of fractures and bone repair [6]. This increases the risk of failure in the integration of any biomaterial implanted into the osteoporotic bone. The need for developing different treatment modalities for the treatment of osteoporotic fractures, improving the osseointegrations of biomaterials applied to those bones, and reducing the risks of failed osseointegrations is critical. Low-level laser therapy (LLLT) as a promising treatment option induces osteogenesis and contributes positively to bone healing [7]. LLLT has been successfully used to improve bone healing after tooth extraction and fractures of bones to accelerate orthodontic tooth movement $[8,9]$. The stimulating effect of LLLT on bone is related to proliferation of fibroblasts and osteoblasts during mesenchymal differentiation. LLLT has also been reported to increase the number of collagen fibers in bones [10]. The increase in tissue vascularization by LLLT stimulates the production of bone matrix and improves bone healing by the release of mediators $[8$, 10, 11]. These positive effects of LLLT on bone healing are thought to improve osseointegration of dental implants in low-density bones.

The primary aim of this study is to increase the osseointegration of dental implants applied to the osteoporotic bone with the biostimulatory effect of LLLT.

\section{Materials and methods}

\section{Animals}

Twenty-two New Zealand (Oryctolagus cuniculus L.) adult female rabbits aged 8 months were used in the study. At the beginning of the study, veterinarians performed a health check. All animal procedures were approved by the Erciyes University Experimental Animal Ethics Committee and performed in compliance with the guidelines for the care and handling of experimental animals of the medical research center at Erciyes University, Kayseri, Turkey.

\section{Group design}

The rabbits were randomly divided into two groups: sham ovariectomy (shamOVX, n:11) and bilateral ovariectomy (OVX, n:11) (Fig. 1). LLLT was applied to the right tibial bones of each rabbit, but not to the left tibial bones. Group shamOVX was divided into two subgroups after ovariectomy and implantation: group shamOVXLLLT $(n: 11)$ and group shamOVX $(n: 11)$. And group OVX was divided into two subgroups after ovariectomy and implantation: group OVX-LLLT $(n: 11)$ and group $\operatorname{OVX}(n: 11)$

\section{Experimental design}

A total of $44(4.1 \times 6 \mathrm{~mm})$ tissue-level SLA implant (Bilimplant ${ }^{\circ}$, Turkey) placements were planned at the left and right tibia metaphysis of all rabbits. In the second (OVX) group, ovariectomy was performed before implantation, and an osteoporosis model was established to reduce bone quality and density. Ovariectomy was performed under general anesthesia with intramuscular ketamine (Ketalar $50 \mathrm{~mL}, 50 \mathrm{mg} / \mathrm{mL}$, Pfizer, UK) and xylazine (Rompun $25 \mathrm{~mL}, 100 \mathrm{mg} / \mathrm{mL}$, Bayer HealthCare, USA). After 2 weeks, methylprednisolone (Prednol-1 ${ }^{\circ} 40 \mathrm{mg}, 1$ ampoule, Mustafa Nevzat, Turkey) was given intramuscularly for 4 weeks with $1 \mathrm{mg} / \mathrm{kg} /$ day to accelerate osteoporosis formation. At the end of this 6week period, the implants were placed in the second group. To prevent the development of infection, $50 \mathrm{mg} /$ $\mathrm{kg}$ of cefazolin (Cefamezin ${ }^{\circ}$ IM Vial, Eczacibasi, Turkey) was injected intramuscularly in the pre- and postoperative periods for 3 days. Also, $1 \mathrm{mg} / \mathrm{kg}$ diclofenac (Diklofen ${ }^{\circ}$ Turkey) as an analgesic was injected intramuscularly for pain control. Both groups were subdivided into two subgroups, and LLLT was applied to the implants placed in the right tibial bone, whereas the left tibial bone was not applied (Fig. 1). A 940-nm wavelength diode laser (BIOLASE Technology Inc., Irvine, CA, USA) was used for LLLT. The laser device was used as a continuous wave at a $0.3 \mathrm{~W}$ output power and was applied at a distance of $1.5 \mathrm{~cm}$ from the implants. Implants were exposed to LLLT from four points at $20 \mathrm{~s} /$ $\mathrm{cm}^{2}$ with at least $6 \mathrm{~J} / \mathrm{cm}^{2}$ of energy and $0.3 \mathrm{~W}$ of power. Laser application was started immediately after surgery and was continued for 10 days. Six weeks after the implants placement, rabbits were euthanized by induction of respiratory depression with high doses of anesthetic agents. The tibial bones in which the implants were placed were removed. After the microtomographic analyses, a stability test with periotest and removal torque values were evaluated.

\section{Micro-computed tomography (CT) analysis}

In this study, a micro-CT (SkyScan-1272, Bruker, Kontich, Belgium) device at Erciyes University Faculty of Dentistry Research Laboratories was used. Features of micro-CT device was used in this study; X-ray source; 20-100 kV, $10 \mathrm{~W}(<5 \mu \mathrm{m}$ spot size at $4 \mathrm{~W})$, X-ray camera; $16 \mathrm{MP}, 4904 \times 3280$ px or $11 \mathrm{MP}, 4032 \times 2668$, pixel size at maximum magnification; the expression < $0.35 \mu \mathrm{m}$ for $16 \mathrm{MP}$ camera is $<0.45 \mu \mathrm{m}$ for $11 \mathrm{MP}$ camera. The dental implant and bone contact surface area was examined in 2 to 3 dimensions, and the $2-\mathrm{mm}$ area of the bone around the implant was measured. Before the implants were scanned, the micro-CT was set up to a $0.5-\mathrm{mm}$ aluminum $(\mathrm{Al})$-copper $(\mathrm{Cu})$ filter, $0.2^{\circ}$ rotation state, 5 -micron pixel size, $4 \mathrm{~K}$ resolution, and $360^{\circ}$ shot. All implants were scanned at the same time. The NRecon v.1.6.3 software (Bruker-microBT, Belgium) program was used to transform the data obtained from the 


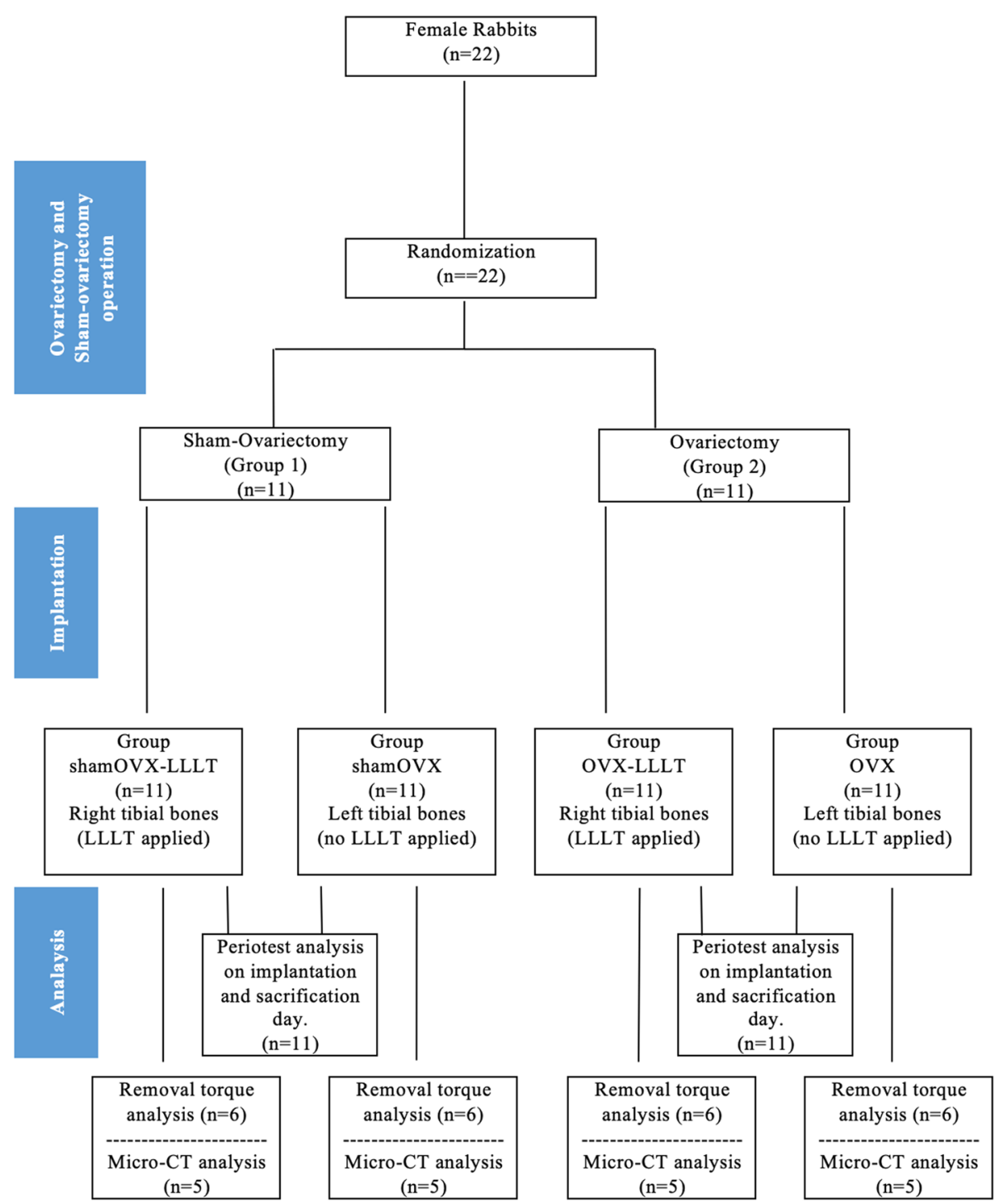

Fig. 1 Group design

scanned implants, and the CTAn v.1.12 software (Bruker-micro-CT, Belgium) program was used for analysis. Images were reconstructed with NRecon 1.6.3 software (Bruker-micro-CT, Belgium) using 35 section hardening correction, 8 ring artifact correction, and minimum and maximum contrast limits, resulting in an average of 1800 cross-sections for each sample. All datasets were segmented and standardized with a user-defined global threshold. A fixed threshold range of 115 to 255 was applied to the image of all implants, and a threshold range of 35 to 255 was applied to the image of all bone tissue (CTAn v.1.12 software (Bruker-micro-CT, Belgium).

In micro-CT, percent intersection surface (IS/TS\%; bone-implant contact surface), percent bone volume (BV/TV\%; bone surface/total volume\%), bone surface density (BS/TV $\mathrm{mm}^{-1}$; bone surface/total volume), connectivity density (Conn.Dn $\mu \mathrm{m}^{-3}$ ), total porosity percent $(\mathrm{Po}$ (tot)\%), and trabecular thickness (Tb.Th $\mu \mathrm{m})$ were measured. These data provided information on implant osseointegration and peri-implant trabecular microstructure.

\section{Periotest analysis}

The Periotest M (Medizintechnik Gulden, Germany) device was used to assess the stability of the implants. Periotest measurement values between -8 and +50 are obtained. The lower the value indicated in the test, the better the stability of the measured tooth or implant [12]. The periotest device evaluates stabilization through a healing cap. Thus, to standardize the periostest measurements, all healing caps were set at $10 \mathrm{Ncm}$ of torque with a rotary instrument. In this study, measurements 
were made at four different points: medial, distal, proximal, and lateral sides of the implants. Measurements were made twice, when implants were placed (T0) and after euthanization (T1); the obtained results were recorded.

\section{Removal torque test}

The tibial samples were wrapped in saline solutionsoaked gauze and stored at $-20{ }^{\circ} \mathrm{C}$; they were then thawed at room temperature on the day of mechanical testing. Gradually increasing unscrewing torque was applied to the implants, and the peak torque value required for loosening the implants was recorded with a digital torque gauge (MARK-10 MTT01-12, NY, USA).

\section{Statistical analysis}

The data of the study was reviewed by an independent statistician. Statistical analysis was performed with SPSS software (SPSS version 15, Chicago, IL, USA). Data regarding periotest, removal torque test, and micro-CT analysis were statistically analyzed with the KruskalWallis non-parametric test, and multiple comparisons were made with the Mann-Whitney $U$ test and one-way analysis of variance (ANOVA). Paired data from initial and final periotest measurements (T0 and T1) were analyzed with the Wilcoxon signed rank test and paired $\mathrm{t}$ test. A $p$ value of .05 was considered significant.

\section{Results}

\section{Removal torque testing tesults}

The mean removal torque values of group shamOVXLLLT $(74.6 \pm 15.4 \mathrm{Ncm})$ were significantly higher than the other groups $(p<0.05)$. In group OVX-LLLT, the mean removal torque value $(56.1 \pm 5.1 \mathrm{Ncm})$ were higher than that from group shamOVX $(55.4 \pm 18.5$ $\mathrm{Ncm})$. But there was no statistically significant difference $(p=0.92)$. The mean value of group OVX-LLLT (56.1 \pm $5.1 \mathrm{Ncm})$ was significantly higher than that of group OVX $(34.4 \pm 7.4)(p<0.05)$ (Table 1).

\section{Periotest stability results}

The mean T0 (implantation day) value for group shamOVX-LLLT, group shamOVX, groupOVX-LLLT, and groupOVX were as follows: - 5.60 (shamOVXLLLT), - 5.33 (shamOVX), - 1.39 (groupOVX-LLLT), and - 1.07 (groupOVX). At T1(euthanized day) values, the mean values obtained were as follows: -7.22 (group sham OVX-LLLT), - 5.80 (group shamOVX), -6.25 (group OVX-LLLT), and - 3.88 (group OVX).

The mean $\mathrm{T} 1$ value was found to be significantly higher than T0 in group shamOVX-LLLT $(p=0.01)$. In group shamOVX, the T1 mean was higher than that at T0, but this difference was not statistically significant ( $p$ $=0.44)$. The mean $\mathrm{T} 1$ value was significantly higher than that at T0 in group OVX-LLT $(p<0.001)$. The mean T1 values of group OVX were significantly higher than at T0 $(p<0.001)$. The greatest difference between T1 and T0 was found in the osteoporotic laser group (group OVX-LLLT) (Table 2).

The mean values of T0 between the shamOVXLLLT and shamOVX groups were not significant ( $p=$ 0.67). Also, the mean values of T0 between the OVXLLLT and OVX groups were not significant $(p=$ 0.62 ). The mean values of T0 between the ovariectomized and non-ovariectomized groups were statistically significant $(p<0.05)$. The mean T1 value of group shamOVX-LLLT was significantly higher than the mean T1 of all other groups $(p<0.05)$. The difference between the T1 periotest values of group shamOVX and group OVX-LLLT was not statistically significant $(p=0.14)$ (Table 2$)$.

\section{Micro-CT result}

The high-resolution 3D images and 2D graphs obtained from micro-CT clearly depicted the differences among the four groups, and the data are shown in Table 3. These results also show the information on implant osseointegration and peri-implant trabecular microstructure (Fig. 2 and Fig. 3).

Table 1 The mean of the RTQ (removal torque) values and the difference between the groups

\begin{tabular}{|c|c|c|c|c|c|c|}
\hline \multirow{6}{*}{$\begin{array}{l}\text { Removal torque } \\
\text { results RTQ }(\mathrm{Ncm})\end{array}$} & \multicolumn{6}{|c|}{ The mean of the RTQ (removal torque) values. Standard deviation (SD) and number of subjects ( $n$ ) } \\
\hline & \multicolumn{2}{|c|}{$\begin{array}{l}\text { Group shamOVX-LLLT } \\
{[\text { mean } \pm S D(n)]}\end{array}$} & $\begin{array}{l}\text { Group shamOVX } \\
\text { [mean } \pm S D(n)]\end{array}$ & \multicolumn{2}{|l|}{$\begin{array}{l}\text { Group OVX-LLLT } \\
{[\text { mean } \pm S D(n)]}\end{array}$} & $\begin{array}{l}\text { Group OVX } \\
{[\text { Mean } \pm S D(\mathrm{n})]}\end{array}$ \\
\hline & \multicolumn{2}{|l|}{$74.6 \pm 15.4(6)$} & $55.4 \pm 18.5(6)$ & \multicolumn{2}{|l|}{$56.1 \pm 5.1(6)$} & $34.4 \pm 7.4(6)$ \\
\hline & \multicolumn{6}{|c|}{ Differences in mean values of RTQ values between groups } \\
\hline & $\begin{array}{l}\text { Group } \\
\text { ShamOVX(LLLT)- } \\
\text { OVX }\end{array}$ & $\begin{array}{l}\text { Group } \\
\text { ShamOVX(LLLT)- } \\
\text { ShamOVX }\end{array}$ & $\begin{array}{l}\text { Group } \\
\text { ShamOVX(LLLT) - } \\
\text { OVX(LLLT) }\end{array}$ & $\begin{array}{l}\text { Group } \\
\text { OVX(LLLT)-OVX }\end{array}$ & $\begin{array}{l}\text { Group } \\
\text { ShamOVX-OVX(LLLT) }\end{array}$ & $\begin{array}{l}\text { Group } \\
\text { ShamOVX-OVX }\end{array}$ \\
\hline & $40.1^{* *}$ & $19.2^{*}$ & $18.5^{*}$ & $21.6^{*}$ & 0.71 & $20.9^{*}$ \\
\hline
\end{tabular}


Table 2 The mean periotest values at T0 (implantation day) and T1 (euthanization day) periods, intra-group comparison of T1-T0 differences and comparison of $\mathrm{T} 0$ and $\mathrm{T} 1$ values between groups

\begin{tabular}{|c|c|c|c|c|c|c|}
\hline & $\begin{array}{l}\text { Group shamOVX-LLLT } \\
{[\text { mean } \pm \mathrm{SD}(n)]}\end{array}$ & \multicolumn{2}{|l|}{$\begin{array}{l}\text { Group shamoVX } \\
{[\text { mean } \pm \mathrm{SD}(n)]}\end{array}$} & $\begin{array}{l}\text { Group OVX-LLLT } \\
{[\text { mean } \pm \mathrm{SD}(n)]}\end{array}$ & \multicolumn{2}{|l|}{$\begin{array}{l}\text { Group (OVX) } \\
\text { [mean } \pm \text { SD (n)] }\end{array}$} \\
\hline Periotest T0 & $-5.60 \pm 1.6(11)$ & \multicolumn{2}{|l|}{$-5.33 \pm 2.1(11)$} & $-1.39 \pm 1.2(11)$ & \multicolumn{2}{|l|}{$-1.07 \pm 0.6(11)$} \\
\hline Periotest T1 & $-7.2 \pm 0.6(11)$ & \multicolumn{2}{|l|}{$-5.8 \pm 0.5(11)$} & $-6.2 \pm 0.5(11)$ & \multicolumn{2}{|l|}{$-3.8 \pm 0.9(11)$} \\
\hline \multicolumn{7}{|c|}{ Comparison of the differences of T1-T0 periotest values } \\
\hline \multirow[t]{2}{*}{ Periotest T1-T0 } & $\begin{array}{l}\text { Group shamOVX-LLLT } \\
\text { (T1-T0) }\end{array}$ & \multicolumn{2}{|l|}{$\begin{array}{l}\text { Group shamoVX } \\
\text { (T1-T0) }\end{array}$} & $\begin{array}{l}\text { Group OVX-LLLT } \\
\text { (T1-T0) }\end{array}$ & \multicolumn{2}{|l|}{$\begin{array}{l}\text { Group (OVX) } \\
\text { (T1-T0) }\end{array}$} \\
\hline & $-1.6^{*}$ & \multicolumn{2}{|l|}{-0.47} & $-5.2^{* *}$ & \multicolumn{2}{|l|}{$-2.8^{* *}$} \\
\hline \multicolumn{7}{|c|}{ The differences and comparison of the TO and T1 values between groups } \\
\hline & $\begin{array}{l}\text { Group } \\
\text { ShamOVX(LLLT)-OVX }\end{array}$ & $\begin{array}{l}\text { Group } \\
\text { ShamOVX(LLLT)- } \\
\text { ShamOVX }\end{array}$ & $\begin{array}{l}\text { Group } \\
\text { ShamOVX(LLLT)-OVX(LLLT) }\end{array}$ & $\begin{array}{l}\text { Group } \\
\text { OVX(LLLT)-OVX }\end{array}$ & $\begin{array}{l}\text { Group } \\
\text { ShamOVX-OVX(LLLT) }\end{array}$ & $\begin{array}{l}\text { Group } \\
\text { ShamOVX-OVX }\end{array}$ \\
\hline Periotest T0 & $-4.5^{* *}$ & -0.2 & $-4.2^{* *}$ & -0.3 & $-3.9^{* *}$ & $-4.2^{* *}$ \\
\hline Periotest T1 & $-3.3^{* *}$ & $-1.4^{* *}$ & $-0.9^{*}$ & $-2.3^{* *}$ & -0.4 & $-1.9^{* *}$ \\
\hline
\end{tabular}

Standard deviation (SD), number of subjects $(n)$

* Statistical difference between groups, $p<0.05$

**Statistical difference between groups, $p<0.001$

\section{Percent intersection surface (bone-implant contact surface) (IS/TS\%)}

The results of the analysis showed that the values in group OVX were lower than those in group shamOVX. The cause of this result was thought to be a decrease in bone quality and density due to the formation of osteoporosis. The mean percent intersection surface values of group shamOVXLLLT $(51.1 \pm 3.2 \%)$ were higher than those of all groups. The mean of group OVX-LLLT $(43.5 \pm 3.1 \%)$ was lower than the mean of group shamOVX-LLLT $(51.1 \pm 3.2 \%)$ and group shamOVX $(45.6 \pm 3.9 \%)$. However, the mean value of group OVX-LLLT was close to group shamOVX, and the difference between these two groups was not statistically significant $(p=0.4)$. In group OVX, the percent intersection surface means $(35.3 \pm 6.1 \%)$ were significantly lower than those in all other groups $(p<0.05)$ (Tables 3 and 4$)$. This result was attributed to osteoporosis formation.

\section{Percentage of bone volume (BV/TV\%)}

The difference of percent bone volume between group shamOVX-LLLT and OVX $(p<0.001)$, group shamOVX-
LLLT and OVX-LLLT ( $p=0.009$ ), and group shamOVX and OVX $(p=0.004)$ was statistically significant. The mean percent bone volume values of group shamOVX-LLLT (47.7 $\pm 2.2 \%$ ) were higher than those of the other groups. It was determined that obtained values of group OVX (28.3 \pm $8.93 \%)$ were lower than those of all the other groups, and the decrease in bone quality and density due to osteoporosis was considered to have resulted from this. The mean of group OVX-LLLT values $(35.7 \pm 6.02 \%)$ was lower than that of closed group shamOVX (41.8 $\pm 6.1 \%)$, but the difference was not statistically significant $(\mathrm{p}=0.14)$ (Tables 3 and 4$)$.

\section{Bone surface density (BS/TV $\mathrm{mm}^{-1}$ )}

Bone surface density was examined, and the mean of group shamOVX-LLLT values $\left(42.8 \pm 3.8 \mathrm{~mm}^{-1}\right)$ was higher than those of all the groups. The mean of group OVX values $\left(26.5 \pm 8.2 \mathrm{~mm}^{-1}\right)$ was the lowest. These results also support osteoporosis. Statistical analysis between the groups showed there was a significant difference between groups shamOVX-LLLT and OVX, groups shamOVX-LLLT and OVX-LLLT, and groups shamOVX

Table 3 The mean of micro- $C T$ parameters according to groups

\begin{tabular}{lllll}
\hline & $\begin{array}{l}\text { Group shamOVX-LLLT } \\
\text { [mean } \pm \text { SD }(\boldsymbol{n}) \text { ] }\end{array}$ & $\begin{array}{l}\text { Group shamOVX } \\
\text { [mean } \pm \text { SD (n)] }\end{array}$ & $\begin{array}{l}\text { Group OVX-LLLT } \\
\text { [mean } \pm \text { SD (n)] }\end{array}$ & $\begin{array}{l}\text { Group OVX } \\
\text { [mean } \pm \text { SD (n)] }\end{array}$ \\
\hline Percent intersection surface (IS/TS\%) & $51.1 \pm 3.2(5)$ & $45.6 \pm 3.9(5)$ & $43.5 \pm 3.1(5)$ & $35.3 \pm 6.1(5)$ \\
Percent of bone volume (BV/TV\%) & $47.7 \pm 2.2(5)$ & $41.8 \pm 6.1(5)$ & $35.7 \pm 6.02(5)$ & $28.3 \pm 8.9(5)$ \\
Bone surface density (BS/TV mm ${ }^{-1}$ ) & $42.8 \pm 3.8(5)$ & $37.7 \pm 9.4(5)$ & $31.8 \pm 10.08(5)$ & $26.5 \pm 8.2(5)$ \\
Connectivity density (Conn.Dn mm $^{-3}$ ) & $7.6 \pm 1.8(5)$ & $6.5 \pm 2.8(5)$ & $4.7 \pm 2.2(5)$ & $3.5 \pm 2.9(5)$ \\
Total porosity percent (Po(tot)\%) & $52.2 \pm 2.2(5)$ & $58.1 \pm 6.1(5)$ & $64.2 \pm 6.02(5)$ & $71.6 \pm 8.9(5)$ \\
Trabecular thickness (Tb.Th $\mu \mathrm{m})$ & $156.3 \pm 20.5(5)$ & $124.1 \pm 20.03(5)$ & $82.06 \pm 23.7(5)$ & $69.2 \pm 30.2(5)$ \\
\hline
\end{tabular}

Mean, standard deviation (SD) and number of subjects $(n)$ 

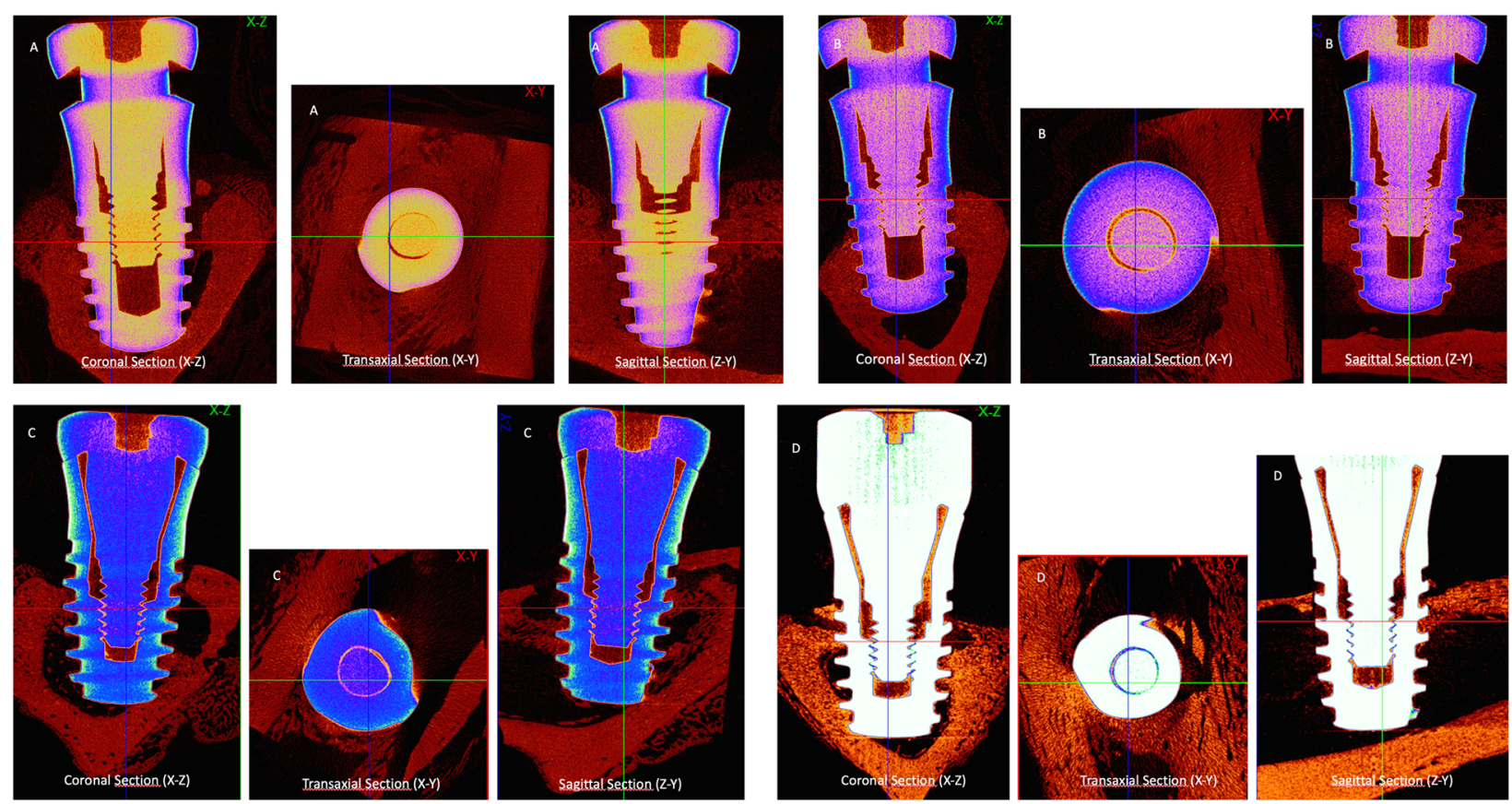

Fig. 2 Images of coronal $(X-Z)$, transaxial $(X-Y)$, and sagittal $(Z-Y)$ sections of the groups in the micro-CT scans. Note the bone implant contact differences among the groups. a ShamOVX-LLLT, b ShamOVX, c OVX-LLLT, and d OVX

and OVX $(p<0.05)$. The differences between the other groups were not statistically significant (Tables 3 and 4 ).

\section{Connectivity density (Conn. Dn $\mu^{-3}$ )}

As a result of connectivity density analysis, the difference between groups shamOVX-LLLT and OVX was found to be significant $(p=0.03)$. The highest mean values of connectivity density were in group shamOVX-LLLT $(7.6$ $\left.\pm 1.8 \mathrm{\mu m}^{-3}\right)$. The lowest value was obtained in group OVX $\left(3.5 \pm 2.9 \mu \mathrm{m}^{-3}\right)$ (Tables 3 and 4$)$.

\section{Total porosity percent (Po (tot)\%)}

Total porosity percent analysis showed that the difference between groups shamOVX-LLLT and OVX, groups

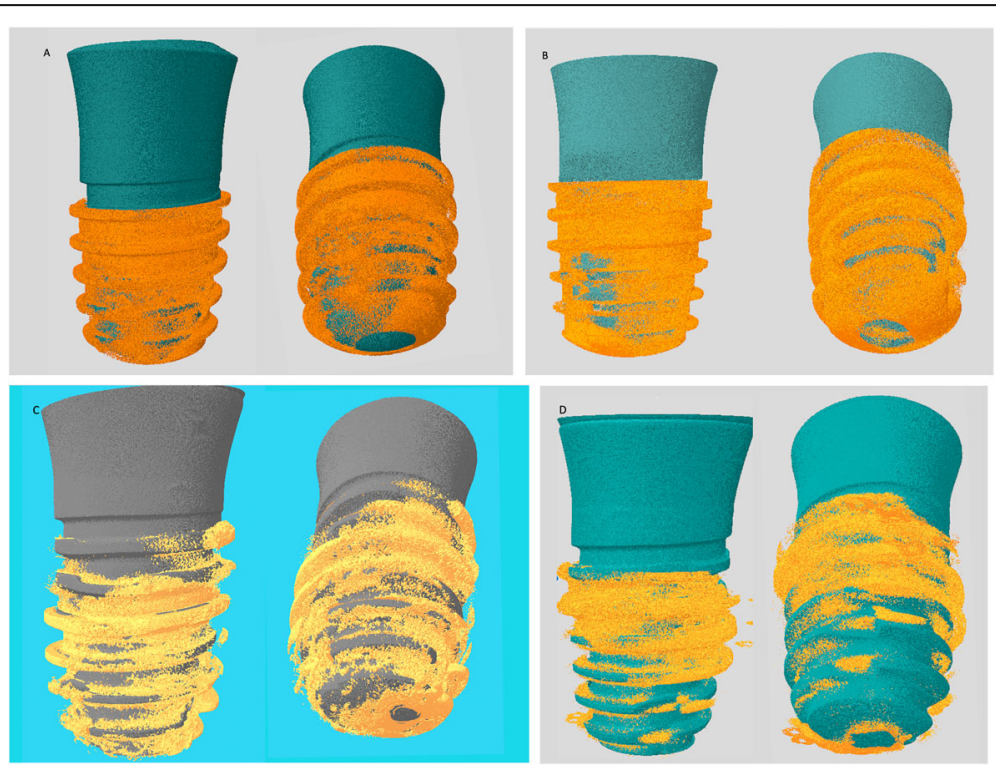

Fig. $33 \mathrm{D}$ images of the new bone formation at peri-implant area in the groups obtained from micro-CT analysis. Note that the increase in the bone volume of the osteoporotic bone around the implant treated with LLLT in OVX-LLLT compared with OVX. a ShamOVX-LLLT, b ShamOVX, c OVX-LLLT, d OVX 
Table 4 Differences in mean values of micro-CT parameters between groups

\begin{tabular}{|c|c|c|c|c|c|c|}
\hline & $\begin{array}{l}\text { Group } \\
\text { ShO(L)-OVX }\end{array}$ & $\begin{array}{l}\text { Group } \\
\text { ShO(L)-ShO }\end{array}$ & $\begin{array}{l}\text { Group } \\
\text { ShO(L)-OVX(L) }\end{array}$ & $\begin{array}{l}\text { Group } \\
\text { OVX(L)-OVX }\end{array}$ & $\begin{array}{l}\text { Group } \\
\text { ShO-OVX(L) }\end{array}$ & $\begin{array}{l}\text { Group } \\
\text { ShO-OVX }\end{array}$ \\
\hline Percent intersection surface (IS/TS\%) & $15.7^{* *}$ & 5.4 & $7.5^{*}$ & $8.2^{*}$ & 2.1 & $10.3^{*}$ \\
\hline Percent of bone volume (BV/TV\%) & $19.4^{* *}$ & 5.9 & $12.07^{*}$ & 7.3 & 6.09 & $13.4^{*}$ \\
\hline Bone surface density (BS/TV $\mathrm{mm}^{-1}$ ) & $16.2^{*}$ & 5.1 & $11.05^{*}$ & 5.2 & 5.9 & $11.1^{*}$ \\
\hline Connectivity density (Conn.Dn $\mu^{-3}$ ) & $4^{*}$ & 1.02 & 2.8 & 1.2 & 1.8 & 3.04 \\
\hline Total porosity percent (Po(tot)\%) & $19.4^{* *}$ & 5.9 & $12.08^{*}$ & 7.3 & 6.1 & $13.4^{*}$ \\
\hline Trabecular thickness (Tb.Th $\mu \mathrm{m})$ & $87.04^{* *}$ & 32.1 & $74.2^{* *}$ & 12.8 & $42.03^{*}$ & $54.8^{*}$ \\
\hline
\end{tabular}

*Statistical difference between groups, $p<0.05$

**Statistical difference between groups, $p<0.001$

ShO(L) group shamOVX-LLLT, ShO group shamOVX, OVX(L) group OVX-LLLT, OVX group OVX

shamOVX-LLLT and OVX-LLLT, and groups shamOVX and OVX was statistically significant $(p<0.05)$. Also, the difference between the groups OVX-LLLT and the shamOVX was not significant $(p=0.14)$. The mean of the group OVX-LLLT total porosity percent $(64.2 \pm$ 6.02) was similar to the mean of group shamOVX (58.1 \pm 6.1 ). The mean of the group shamOVX-LLLT total porosity percent values $(52.2 \pm 2.2 \%)$ was lower than all groups. The mean of the group OVX values (71.6 \pm $8.9 \%)$ was higher than those of other groups. This result was parallel to the formation of the osteoporosis model (Tables 3 and 4).

\section{Trabecular thickness (Tb.Th $\mu \mathrm{m}$ )}

Trabecular thickness analysis showed that the mean trabecular thickness value $(156.3 \pm 20.5 \mu \mathrm{m})$ of group shamOVX-LLLT was higher than that in the other groups. The mean of group OVX $(69.2 \pm 30.2 \mu \mathrm{m})$ was the lowest of all groups. According to these results, the trabecular thickness in the group of osteoporosis decreased significantly $(p<0.001)$. Although the mean trabecular thickness values of group OVX-LLLT (82.06 \pm $23.7 \mu \mathrm{m})$ was higher than group OVX $(69.2 \pm 30.2 \mu \mathrm{m})$, the difference was not statistically significant $(p=0.4)$. The difference between the other groups was statistically significant $(p<0.05)$. Trabecular thickness analysis was showed that the mean of group shamOVX-LLLT $(24.5 \pm$ $9.8 \mu \mathrm{m}$ ) was lower than all other groups (Tables 3 and 4).

\section{Discussion}

Several methods have been developed to increase dental implant osseointegrations. These include mechanical methods, such as modifications of implant surfaces or coating with medical agents, and the methods used to increase biostimulation include vibration and LLLT applications [13-16]. Among these methods, LLLT is one of the more promising methods to improve osseointegration of biomaterials and to prepare an appropriate implant area [8]. Liu et al. indicated that LLLT accelerated fracture healing and increased callus volume, especially at early stages of bone healing [17]. In in vivo comparative studies involving cell cultures, LLLT was found to have positive effects on biostimulation of cells [18]. It has been reported that LLLT may accelerate resorption or formation activities depending on the stages of bone fracture repair [19]. Given the evidence of positive effects of LLLT on bone healing, it is possible to accelerate or increase the osseointegration of implants with LLLT. Khandra et al. pointed out that the osseointegrations of titanium implants accelerated in their studies with LLLT [13]. In the literature, there are a few studies in which dental implants and LLLT are applied in osteoporotic bones. In this study, the authors emphasized that LLLT positively contributed to osseointegration of implants applied to osteopenic rats [20].

It has recently been reported that LLLT should not exceed $1 \mathrm{~W}$ of output power for biostimulation [21]. Biostimulation has been shown to increase in studies with $0.3 \mathrm{~W}$ output power [22-24]. According to this information, $0.3 \mathrm{~W}$ of output power is applied in our study. For LLLT, it is stated that the ideal wavelength is from 550 to $950 \mathrm{~nm}$ [25]. We used $940 \mathrm{~nm}$ at the wavelength diode laser in our study. It was not possible to determine an effective dose on bone tissue, and very different doses were used in the literature [21]. The LLLT protocol we applied in our study is similar to that of Khadara et al. [13]. Factors determining the effect of the laser on the tissues include the tissue that is administered and the penetrating dose. The laser energy transmitted per $\mathrm{cm}^{2}$ area in the target tissue is called energy or dose [21]. The dose was standardized according to the tissues, but since the effective wavelength on the bone tissue of the LLLT was not standard, no protocol could be established [26]. It was seen that an effective dose could not be determined on bone tissue, but different doses were used in the literature. Similar studies in the literature show that 3 to $10 \mathrm{~J} / \mathrm{cm}^{2}$ energy is used for bone tissue [13, 19 , 27]. In this study, $6 \mathrm{~J} / \mathrm{cm}^{2}$ energy was used.

By using some digital test devices such as periotest, resonance frequency analysis can be used to evaluate implant stability [28]. There are many studies in the literature that are used in both devices [29-36]. When the 
literature is examined, periotest is stated to be a reliable device in the diagnosis of implant stability, and current studies using the periotest device are available [32-36]. Also, periotest is a non-invasive diagnostic method that evaluates the stability between the implant surface and the bone [37]. It also has the advantages of being easily portable, ergonomic, cost-effective, practical, and selfsufficient in measuring [12]. Besides these advantages, the fact that it has been used in many studies in the literature has been a factor in the preference of the periotest device in this study. The measurements have been repeated twice. A literature review shows that implants applied to osteoporosis-generated models give lower results in stability tests [38-41]. In the present study, in the group with osteoporosis, the stability test results obtained were lower. Following LLLT, the value in the osteoporosis group exceeds the value of a healthy and non-laser-treated group. The highest increase was obtained in group OVX-LLLT.

Recent studies showed that the mean of the removal torque values of the implants applied to the osteoporosis model bones is lower than the mean of the implants applied to healthy groups [38-41]. The results of this study are consistent with the literature. The mean of the removal torque values of the implants in the shamovariectomy groups was higher in group shamOVXLLLT than group shamOVX. In the osteoporosis group, the mean values of the removal torque were higher in group OVX-LLLT than the group OVX. The mean values of group OVX-LLLT $(56.1 \pm 5.1)$ and shamOVX $(55.4 \pm 18.5)$ were similar, and the difference between them was not statistically significant $(p=0.92)$. Also, the mean of group shamOVX-LLLT was significantly higher than that of all other groups. The removal torque results showed that LLLT application contributed to osseointegration in both osteoporosis and healthy bones. There is a strong, positive, and statistically significant correlation between the percentage of bone volume and RTQ variables ( $r 0.62$ and $p$ 0.003). This result showed that the amount of bone around the implant and the increase of RTQ values were parallel to each other. These values were the lowest in rabbits with experimentally induced osteoporosis.

In determining bone quality, bone density alone does not provide clear information. To predict bone strength and fracture resistance, bone should be considered together with micro-structure [42]. Currently, histomorphometric evaluation and micro-CT examination are included in the evaluation of the quality and density of the bone. As stated in the literature, histomorphometry is still known today as the most effective method for determining bone-implant contact (BIC) and bone formation at a cell level. Also, BIC and peri-implant bone density (BV/TV) were traditionally obtained by histology and serve biological implant integration [43].. Nevertheless, histomorphometry is a destructive method, and the same sample cannot be used in the evaluation of other tests such as removal torque and stability evaluation [44]. In particular, the data obtained in evaluating new bone formation are limited to 2D images data do not reflect the actual 3D structure of bone [44]. In addition, the process of completion of the analysis is quite long [43]. Therefore, a non-invasive method is needed to evaluate osseointegration. Microcomputer tomography (micro-CT) has taken its place in the literature as a nondestructive technique that allows precise quantitative three-dimensional (3D) analysis. Micro-CT is accepted as the gold standard for assessment of trabecular microstructure [45]. The pixel, which forms the 2D or 3D cross-sectional images obtained by micro-CT, is in the micro dimension, allowing the internal structure of a material to be displayed in three dimensions in a nondestructive manner and the measurements made accordingly [46]. Micro-CT can analyze the data for the bone up to a few microns on the implant surface and in the periimplant area and evaluate both the qualitative and quantitative morphometry of implant bone integration [47]. Despite all advantages, there are studies indicating that micro-CT is not as effective as histomorphometry in evaluating bone-implant contact. Thus, in this study, both biomechanical tests and morphometric analyses and bone-implant contact obtained from micro-CT were used to evaluate osseointegration. However, there are also micro-CT studies in which the connection in the bone implant interface is evaluated by $\mathrm{BIC}, \mathrm{BV} / \mathrm{TV}$, trabecular thickness, trabecular number, and trabecular separation [48-50].

There are studies in which micro-CT and histomorphometric analysis have been used to evaluate dental implant osseointegration comparatively [43, 51, 52]. He, Tao et al. In their current study, compared bone density using micro-CT and Histomorphometric analysis and stated that there was a correlation among them [43]. In the studies of Vandeweghe et al., they compared the bone density and bone-implant contact of micro-CT and Histomorphometry, it was found that there was a correlation between the data [51]. Diefenbeck et al.'s study, it was evaluated osseointegration, they reported that boneimplant contact (BIC) showed good correlation with biomechanical tests and was a more important parameter than bone area density (BA) in evaluating osseointegration [53]. Also, in Bissinger et al. they compared the bone-implant contact (BIC\%) of micro-CT and histomorphometry, it was found that there was a correlation between the data too [52]. In the present study, a similar correlation was obtained between BIC value and biomechanical tests. It was seen that the obtained results are compatible with the literature. There is a strong, 
positive, and statistically significant correlation between the percentage of bone volume (BV/TV\%) and RTQ variables $(r 0.62$ and $p 0.003)$ and between the percentage of bone volume (BV/TV\%) and bone-implant contact (BIC\%) $(r 0.75$ and $p<0.001)$, and there is a positive, moderate, and statistically significant correlation between the bone-implant contact (BIC\%) and RTQ variables ( $r 0.59$ and $p$ 0.006) (Table 5).

In similar studies with micro-CT, percent intersection surface, percent bone volume, bone surface density, connectivity density, trabecular thickness, and trabecular separation parameters were investigated [54-59]. These values have also been examined in the present study. In this study, the percent bone volume value parallel to other studies. Percent bone volume values in the group OVX-LLLT, which was osteoporotic bone treated with LLLT, was higher than in the osteoporotic control group (group OVX) and close to the healthy control group (group shamOVX). These results showed that there is a positive effect of LLLT on osteoporotic bones.

In this study, bone-implant contact values were higher in the healthy bone treated with LLLT (group shamOVX-LLLT) than in the healthy control group (group shamOVX), in osteoporotic bone treated with LLLT (group OVX-LLLT), and in the osteoporotic control group (group OVX). The difference between the osteoporotic bone treated with LLLT and the osteoporotic control groups was found to be statistically significant, and the mean values of the group OVX-LLLT came close to those of the healthy control group. These results support a positive effect of LLLT on osseointegration of implant in osteoporotic bones.

Trabecular thickness, bone surface density, total porosity percent, and total volume of pore space values are used as the markers of osteoporosis in micro-CT analyses. Some studies showed that trabecular thickness and bone surface density values decreased, whereas total porosity percent and the total volume of pore space values increased in osteoporotic bones [55, 57]. In this study, the trabecular thickness and bone surface density values decreased, whereas the total porosity percentage and total volume of pore space values increased in the ovariectomized rabbits compared with the healthy group. These values in the osteoporosis group treated with

Table 5 Correlation analysis

\begin{tabular}{lll}
\hline & Correlation & $\boldsymbol{p}$ value \\
\hline $\begin{array}{l}\text { BV/TV\% (percentage of bone volume): } \\
\text { RTQ Ncm (removal torque analysis) }\end{array}$ & 0.62 & 0.003 \\
$\begin{array}{l}\text { BV/TV\% (percentage of bone volume): } \\
\text { IS/TS\% (bone-implant contact surface) }\end{array}$ & 0.75 & $p<0.001$ \\
$\begin{array}{l}\text { IS/TS\% (bone-implant contact surface): } \\
\text { RTQ Ncm (removal torque analysis) }\end{array}$ & 0.59 & 0.006 \\
\hline
\end{tabular}

LLLT were close to the values of the healthy control group in micro-CT analysis.

\section{Conclusions and declarations}

In this experimental study, all values obtained from biomechanical tests and micro-CT in the OVX-LLLT group were significantly higher than that of the OVX group and achieved the values in the healthy bone. These results show that LLLT has a positive effect on osseointegration of implants placed in osteoporotic bone. The fact that laser therapy is a non-invasive technique, there are studies with positive effects, this study also supports positive effects, and may provide more clinical studies on the effects of low-dose laser therapy on implant osseointegration. Further clinical trials are needed to evaluate the clinical efficacy and safety of the results obtained from this experimental study.

\section{Supplementary information}

Supplementary information accompanies this paper at https://doi.org/10. 1186/s40729-020-00257-z.

Additional file 1. Video images obtained from Micro-CT.

\section{Abbreviations}

LLLT: Low-level laser therapy; ShamOVX: Sham ovariectomy;

OVX: Ovariectomy; IS/TS: Bone-implant contact surface; BV/TV: Percent of bone volume; BS/TS: Bone surface density; Conn. Dn: Connectivity density; Po (tot): Total porosity percent; Tb.Th: Trabecular thickness

\section{Authors' contributions}

Both authors worked together in the preparation of the article, in the experimental stage, in the collection and analysis of data, and in the writing of the manuscript. The author(s) read and approved the final manuscript.

\section{Funding}

This study was supported by Erciyes University Scientific Research Projects Unit, project TDH- 2017-7860.

\section{Ethics approval and consent to participate}

This study was approved by the Erciyes University Experimental Animal Ethics Committee and performed in compliance with the guidelines for the care and handling of experimental animals of the medical research center at Erciyes University, Kayseri, Turkey. (Reference number: 2017/111).

\section{Consent for publication}

Consent to publish was obtained from all applicable parties.

\section{Competing interests}

The authors declare that they have no competing of interests.

\section{Author details}

${ }^{1}$ Sancaktepe Oral and Dental Health Hospital, Department of Oral and Maxillofacial Surgery, Ministry of Health, İstanbul, Turkey. ${ }^{2}$ Department of Oral and Maxillofacial Surgery, Erciyes University Faculty of Dentistry, Melikgazi, Kayseri, Turkey.

Received: 27 January 2020 Accepted: 31 August 2020

Published online: 12 October 2020

References

1. Legeros RZ, Craig RG. Strategies to affect bone remodeling: osteointegration. J Bone Mineral Res. 1993;8(S2):583-96. 
2. Erinç Ö. Determination of Bone Quality in Dentistry: Radiographic Methods and Interpretations. J Ondokuz Mayıs Univ Faculty Dentistry. 2007;8:190-9.

3. Consensus A. Consensus development conference: diagnosis, prophylaxis, and treatment of osteoporosis. Am J Med. 1993;94(6):646-50.

4. Tsolaki IN, Madianos PN, Vrotsos JA. Outcomes of dental implants in osteoporotic patients. A literature review. J Prosthodont Implant Aesthet Reconstr Dent. 2009;18(4):309-23.

5. Hollinger JO, et al. Accelerated fracture healing in the geriatric, osteoporotic rat with recombinant human platelet-derived growth factor-bb and an injectable beta-tricalcium phosphate/collagen matrix. J Orthopaedic Res. 2008;26(1):83-90.

6. Organization, W.H., Prevention and management of osteoporosis: report of a WHO scientific group. 2003: World Health Organization.

7. Sarvestani FK, et al. Effect of low-level laser therapy on fracture healing in rabbits. Laser therapy. 2017;26(3):189-93.

8. Pinheiro ALB, Gerbi MEM. Photoengineering of bone repair processes. Photomed Laser Ther. 2006;24(2):169-78.

9. Nissan J, et al. Effect of low intensity laser irradiation on surgically created bony defects in rats. J Oral Rehab. 2006;33(8):619-924.

10. Pires Oliveira DA, et al. Evaluation of low-level laser therapy of osteoblastic cells. Photomed Laser Surg. 2008;26(4):401-4.

11. Shakouri SK, et al. Effect of low-level laser therapy on the fracture healing process. Lasers in medical science. 2010;25(1):73.

12. Gökçe D. The methods of dental implant stability. Yeditepe J Dent. 2018; 14(1):81-6.

13. Khadra M, et al. Low-level laser therapy stimulates bone-implant interaction: an experimental study in rabbits. Clin Oral Implants Res. 2004;15(3):325-32.

14. Bagno A, Di Bello C. Surface treatments and roughness properties of Tibased biomaterials. J Mater Sci. 2004;15(9):935-49.

15. Josse $\mathrm{S}$, et al. Chemically modified calcium phosphates as novel materials for bisphosphonate delivery. Advanced Materials. 2004;16(16):1423-7.

16. Chen B, et al. Low-magnitude high-frequency loading via whole body vibration enhances bone-implant osseointegration in ovariectomized rats. J Orthopaedic Res. 2012;30(5):733-9.

17. Liu $X$, et al. Effect of lower-level laser therapy on rabbit tibial fracture. Photomed Laser Surg. 2007;25(6):487-94.

18. Khadra M, et al. Effect of laser therapy on attachment, proliferation and differentiation of human osteoblast-like cells cultured on titanium implant material. Biomaterials. 2005;26(17):3503-9.

19. Nicola RA, et al. Effect of low-power GaAlAs laser $(660 \mathrm{~nm})$ on bone structure and cell activity: an experimental animal study. Lasers Med Sci. 2003;18(2):89-94.

20. de Vasconcellos LMR, et al. Healing of normal and osteopenic bone with titanium implant and low-level laser therapy (GaAlAs): a histomorphometric study in rats. Lasers Med Sci. 2014;29(2):575-80.

21. Miserendino LJ, Levy G, Miserendino CA. Laser interaction with biologic tissues. In: Miserendino LJ, Pick RM, editors. Laser in Dentistry. Chicago: Quintessence; 1995. p. 39-56.

22. Lirani-Galvão AP, Jorgetti V, Da Silva OL. Comparative study of how lowlevel laser therapy and low-intensity pulsed ultrasound affect bone repair in rats. Photomedicine and Laser Therapy. 2006;24(6):735-40.

23. Fávaro-Pípi E, et al. Comparative study of the effects of low-intensity pulsed ultrasound and low-level laser therapy on bone defects in tibias of rats. Lasers in medical science. 2010;25(5):727-32.

24. Goymen $\mathrm{M}$, et al. Histomorphometric evaluation of the effects of various diode lasers and force levels on orthodontic mini screw stability. Photomedicine and laser surgery. 2015;33(1):29-34.

25. Glinkowski W, P.L, Lasers in therapy. Warsaw. 2001.

26. S.P. Low-Level Laser Use in Dentistry. Br Dental J. 2007;202:131-8.

27. Silva Júnior AN, et al. Computerized morphometric assessment of the effect of low-level laser therapy on bone repair: an experimental animal study. J Clin Laser Med Surg. 2002;20(2):83-7.

28. Dario LJ, Cucchiaro PJ, Deluzio AJ. Electronic monitoring of dental implant osseointegration. J Am Dental Assoc. 2002;133(4):483-90.

29. Nappo A, et al. Influence of implant dimensions and position on implant stability: A prospective clinical study in maxilla using resonance frequency analysis. Applied Sciences. 2019;9(5):860.

30. Lages FS, Douglas-de Oliveira DW, Costa FO. Relationship between implant stability measurements obtained by insertion torque and resonance frequency analysis: A systematic review. Clin Implant Dentistry Related Res. 2018;20(1):26-33.
31. Buyukguclu G, Ozkurt-Kayahan Z, Kazazoglu E. Reliability of the Osstell implant stability quotient and penguin resonance frequency analysis to evaluate implant stability. Implant dentistry. 2018;27(4):429-33.

32. Khalaila W, Nasser M, Ormianer Z. Evaluation of the relationship between Periotest values, marginal bone loss, and stability of single dental implants: a 3-year prospective study. J Prosthetic Dentistry. 2020;124(2):183-8.

33. Hakim SG, et al. Correlation of cone beam CT-derived bone density parameters with primary implant stability assessed by peak insertion torque and periotest in the maxilla. J Cranio-Maxillofacial Surg. 2019;47(3):461-7.

34. Flieger $\mathrm{R}$, et al. Low-Level Laser Therapy with a $635 \mathrm{~nm}$ Diode Laser Affects Orthodontic Mini-Implants Stability: A Randomized Clinical Split-Mouth Trial. J Clin Med. 2020;9(1):112.

35. Jeong M-A, et al. Implant stability measurements in the long-term follow-up of dentis implants: a retrospective study with periotest. Implant dentistry. 2015;24(3):263-6.

36. Almutairi AS, Walid MA, Alkhodary MA. The effect of osseodensification and different thread designs on the dental implant primary stability [version 1; peer review: 2 approved, 1 approved with reservations]. F1000Research. 2018;7:1898.

37. Meredith $\mathrm{N}$, et al. Relationship between contact time measurements and PTV values when using the Periotest to measure implant stability. Int J Prosthodontics. 1998;11(3):269-75.

38. YIldiz A, et al. Effect of zoledronic acid on osseointegration of titanium implants: an experimental study in an ovariectomized rabbit model. J Oral Maxillofacial Surg. 2010;68(3):515-23.

39. Fujimoto $T$, et al. Effects of steroid-induced osteoporosis on osseointegration of titanium implants. Int J Oral Maxillofacial Implants. 1998; 13(2):183-9.

40. Jung $Y-C$, et al. Effects of ion beam--assisted deposition of hydroxyapatite on the osseointegration of endosseous implants in rabbit tibiae. Int J Oral Maxillofacial Implants. 2001;16(6):809-18.

41. Giro G, et al. Effect of $17 \beta$-estradiol and alendronate on the removal torque of osseointegrated titanium implants in ovariectomized rats. Journal of periodontology. 2007;78(7):1316-21.

42. Diederichs $\mathrm{G}$, et al. Assessment of trabecular bone structure of the calcaneus using multi-detector $\mathrm{CT}$ : correlation with microCT and biomechanical testing. Bone. 2009;44(5):976-83.

43. He T, et al. A comparison of micro-CT and histomorphometry for evaluation of osseointegration of PEO-coated titanium implants in a rat model. Sci Rep. 2017;7(1):1-11.

44. Park S-Y, et al. The evaluation of the correlation between histomorphometric analysis and micro-computed tomography analysis in AdBMP-2 induced bone regeneration in rat calvarial defects. J Periodontal Implant Sci. 2011;41(5):218-26.

45. Burghardt AJ, Link TM, Majumdar S. High-resolution computed tomography for clinical imaging of bone microarchitecture. Clin Orthopaedics Related Res. 2011;469(8):2179-93.

46. Yakıncı ME, et al. Importance of micro-computed tomography (Micro-CT) in health, science and engineering sciences. J Biomed Clin Eng. 2016;81:334-6.

47. Park YS, et al. Correlation between microtomography and histomorphometry for assessment of implant osseointegration. Clin Oral Implants Res. 2005;16(2):156-60.

48. Steiner JA, Ferguson SJ, van Lenthe GH. Computational analysis of primary implant stability in trabecular bone. J Biomechanics. 2015;48(5):807-15.

49. Vandamme $\mathrm{K}$, et al. Establishment of an in vivo model for molecular assessment of titanium implant osseointegration in compromised bone. Tissue Engineering Part C: Methods. 2011;17(3):311-8.

50. Taxt-Lamolle SF, et al. Controlled electro-implementation of fluoride in titanium implant surfaces enhances cortical bone formation and mineralization. Acta biomaterialia. 2010;6(3):1025-32.

51. Vandeweghe $S$, et al. Utilizing micro-computed tomography to evaluate bone structure surrounding dental implants: A comparison with histomorphometry. J Biomed Mater ResPart B: Appl Biomater. 2013;101(7):1259-66.

52. Bissinger $\mathrm{O}$, et al. Comparative $3 \mathrm{D}$ micro-CT and $2 \mathrm{D}$ histomorphometry analysis of dental implant osseointegration in the maxilla of minipigs. J Clin Periodontol. 2017:44(4):418-27.

53. Diefenbeck $M$, et al. The effect of plasma chemical oxidation of titanium alloy on bone-implant contact in rats. Biomaterials. 2011;32(32):8041-7.

54. Freilich $\mathrm{M}$, et al. Implant system for guiding a new layer of bone. Computed microtomography and histomorphometric analysis in the rabbit mandible. Clinical oral implants research. 2009;20(2):201-7. 
55. Monjo $\mathrm{M}$, et al. In vivo expression of osteogenic markers and bone mineral density at the surface of fluoride-modified titanium implants. Biomaterials. 2008;29(28):3771-80.

56. Gao $Y$, et al. Effect of combined local treatment with zoledronic acid and basic fibroblast growth factor on implant fixation in ovariectomized rats. Bone. 2009:44(2):225-32.

57. Li Y, et al. The effect of strontium-substituted hydroxyapatite coating on implant fixation in ovariectomized rats. Biomaterials. 2010;31(34):9006-14.

58. Gabet $Y$, et al. Parathyroid hormone 1-34 enhances titanium implant anchorage in low-density trabecular bone: a correlative micro-computed tomographic and biomechanical analysis. Bone. 2006;39(2):276-82

59. Qi M, et al. Effect of zoledronate acid treatment on osseointegration and fixation of implants in autologous iliac bone grafts in ovariectomized rabbits. Bone. 2012;50(1):119-27.

\section{Publisher's Note}

Springer Nature remains neutral with regard to jurisdictional claims in published maps and institutional affiliations.

\section{Submit your manuscript to a SpringerOpen ${ }^{\circ}$ journal and benefit from:}

- Convenient online submission

- Rigorous peer review

- Open access: articles freely available online

High visibility within the field

- Retaining the copyright to your article

Submit your next manuscript at $\boldsymbol{\nabla}$ springeropen.com 